\title{
1 Coarse woody decay rates vary by physical position in tropical \\ 2 seasonal rainforests of SW China
}

4 Zewei Song ${ }^{\mathrm{a}, \mathrm{b}}$, Christopher Dunn ${ }^{\mathrm{c}}$, Xiao-Tao Lü ${ }^{\mathrm{d}}$, Lu Qiao ${ }^{\mathrm{a}}$, Jia-Ping Pang, Jian-Wei Tang ${ }^{\mathrm{a},{ }^{*}}$

$5{ }^{\text {a }}$ Key Laboratory of Tropical Plant Resources and Sustainable Use, Xishuangbanna Tropical

6 Botanical Garden, Chinese Academy of Sciences, Yunnan 666303, China

$7 \quad{ }^{\mathrm{b}}$ Department of Plant Pathology, University of Minnesota, Twin Cities, MN 55108, USA

$8 \quad{ }^{c}$ College of Forestry, Oregon State University, 280 Peavy Hall, Corvallis, OR 97331, USA

9 d Erguna Forest-Steppe Ecotone Research Station, Key Laboratory of Forest Ecology and

10 Management, Institute of Applied Ecology, Chinese Academy of Sciences, Shenyang 110016,

11 China

12

$13 *$ *uthor for correspondence

14 Dr. Jian-Wei Tang

15 Email: tangjw@xtbg.org.cn

16 Tel: +86-691-8715080

(C) 2016. This manuscript version is made available under the Elsevier user license http://www.elsevier.com/open-access/userlicense/1.0/ 


\section{Abstract}

18 Decomposition of woody detritus is an important but often ignored process in forest ecosystems.

19 Moisture and temperature regimes are dominant controls over woody decay, contributing to

20 significant variability at local, regional, and global scales. Our focus was on local variability in

21 woody decay rates depending on their physical position. Woody detritus may decay on the forest

22 floor, aboveground, or combination of both, depending on the mortality agent. In this study, we

23 measured decay rates of logs, large branches on the forest floor, and snags over a three-year

24 period. We also collected monthly respiration estimates, and analyzed woody detritus $\mathrm{N}$ and $\mathrm{P}$

25 content throughout the study. Logs exhibited the greatest mass loss with a decay-rate constant of

$26 \mathrm{k}=0.606 \pm 0.020)$, followed by large branches $(\mathrm{k}=0.316 \pm 0.012)$ and snags $(\mathrm{k}=0.268 \pm 0.008)$.

27 Heterotrophic respiration was greatest prior to the peak of rainy season, and was greatest for snag

28 material during the first two years of sampling, probably a result of water saturation in ground

29 material. Both $\mathrm{N}$ and $\mathrm{P}$ were released in all materials, but the rate of $\mathrm{P}$ release was much slower in

30 snags. There were large differences of $\mathrm{P}$ concentration and $\mathrm{C}: \mathrm{P}$ among the materials, but their

31 value became similar after three years, indicating P limitation on microbial activities. Our results

32 presented robust evidence for the physical-position-dependence of coarse woody detritus

33 decomposition in the forests.

34 Keywords: decomposition, coarse woody debris, nutrient release, tropical forest, wood 35 decay 
38 Coarse woody detritus (CWD) is a critical component of forested ecosystems where it provides a

39 multitude of ecosystem services. These include structural habitat for multiple vertebrate and

40 invertebrate species (Bull et al., 1997), the primary energy source for saprophyte communities

41 (Norden et al., 2004), and significant contributions to long-term soil development (Tinker and

42 Knight, 2000; Triska and Cromack, 1980). Input and loss rates of woody detritus also have

43 implications on several ecosystem processes, including nutrient cycling and carbon dynamics

44 (Harmon et al., 1986). Despite having relatively low concentrations of nutrients, woody detritus

45 acts as a long-term nutrient pool with a temporal lag in nutrient release relative to more labile

46 material (Laiho et al., 2004). Woody detritus also contributes significantly to long-term carbon

47 storage as the largest detritus pool in forests, with implications on total carbon stores and

48 ecosystem carbon balance (Freschet et al., 2012).

49 Carbon fluxes from decaying wood remain one of the largest uncertainties in

50 biogeochemical models (Chambers et al., 2000). Part of this uncertainty can be attributed to the

51 difficulty in quantifying the cause and extent of woody detritus inputs under various

52 environmental conditions or disturbance events (van Mantgem et al., 2011; McDowell et al.

53 2015). This may be especially difficult since inputs can occur in various physical positions within

54 forests. For example, natural disturbances such as pathogens, insects, wildfires, hurricanes and

55 drought typically produce standing dead trees (snags) with minimal ground contact and increased

56 exposure to solar radiation and drying wind (Harmon, 1982). In contrast, windthrow, ice damage,

57 landslides and logging produce dead stems and branches immediately in contact with the forest

58 floor (Whigham et al., 1991). Most woody detritus research has focused on reducing this

59 uncertainty by quantifying input rates and stocks in various forests under different management

60 and disturbance regimes, but relatively few have estimated decay or flux rates for this material 
61 which is necessary for quantifying net ecosystem carbon balance with biogeochemical models

62 (Keller et al., 2004; Rice et al., 2004; Palace et al., 2007; Yoneda et al. 1990).

63 Woody detritus decomposition and nutrient dynamics, as well as factors contributing to 64 variation in these processes, also remain uncertain in many forested ecosystems. Temperature and 65 moisture regimes are regarded as the dominant controlling factors (Harmon et al., 1986; 66 Chambers et al., 2000; Wang et al., 2002). Warm, moist conditions indicative of rainforest 67 environments promote rapid decay (Chapin et al., 2010), while freezing temperatures inhibit 68 decomposer activity by slowing metabolic processes and saturation creates anaerobic 69 environments that suppress decomposition (Progar and Schowalter, 2000). These factors likely 70 contributed to observed variation in woody decay rates by their physical position, where standing 71 or elevated material decayed slower than materials decomposing on the ground in temperate and 72 boreal coniferous forests (Yatskov et al., 2003, Dunn and Bailey, 2012). This trend has also been 73 observed in temperate deciduous forests where the half-life of snags were 11.2 years, compared to 746.3 years for logs (Onega \& Eickmeier, 1991). Resource accessibility by wood-degrading fungi 75 has also been found to further influences woody decay rates by their physical position (Boddy, 76 1999). The magnitude of these observed differences suggests carbon fluxes and nutrient cycling 77 rates may be lagged when woody detritus is inputted as elevated material, contributing to the 78 long-term immobilization of nutrients (Laiho \& Prescott, 1999). Additionally, initial 79 concentrations of $\mathrm{N}$ and $\mathrm{P}$ have been correlated with both litter and woody decay rates (Laiho et 80 al., 2004; Parton et al. 2007). Obtaining estimates for standing and surface decay rates, as well as 81 the influence of variation in nutrient concentrations, are needed to more accurately model these 82 ecosystem processes and to determine whether or not elevated material embodied a different 83 pathway of decay and nutrient cycling than surface material.

84 In this study, we were interested in characterizing the contribution of woody detritus to 85 carbon fluxes and nutrient cycling in tropical seasonal rainforests of southwest China. Tropical 
86 seasonal rainforests have an obvious transition between dry and wet seasons, so we hypothesized

87 that lower water availability during the dry season would result in variation in decay rates of

88 woody detritus depending on their physical position. Additionally, since phosphorus (P) is

89 considered a limiting factor for productivity in tropical forests, we also hypothesized that $\mathrm{P}$ or the

90 C:P ratio would be closely correlated with the decay rates of this material. Therefore, we studied

91 decomposition of three types of woody detritus in their original decay position to capture the

92 contribution of these factors (position they were originally input into the system). Heterotrophic

93 respiration rate, mass loss, and nutrient dynamics were measured for three years from 2006 to

942008 for woody material from logs and large branches on the ground, as well as standing snags.

95 This study represents the initial investigation of decay dynamics for woody detritus in this forest 96 type.

97

98 Method

99 Experimental site

100 This study was conducted at a long-term research site at the Tropical Rainforest Ecosystem 101 Station of the Chinese Academy of Sciences in Xishuangbanna, Yunnan Province, China $102\left(21^{\circ} 55^{\prime} 39^{\prime \prime} \mathrm{N}, 101^{\circ} 15^{\prime} 55^{\prime} \mathrm{E}\right)$. The climatic conditions of this forest are typical of monsoonal 103 conditions. The 40-year mean annual temperature was $21.7{ }^{\circ} \mathrm{C}$ (minimum of $15.9^{\circ} \mathrm{C}$ and 104 maximum of $25.7^{\circ} \mathrm{C}$ ) and a mean annual precipitation was $1539 \mathrm{~mm}$. On average, $87 \%$ of 105 precipitation occurs during the rainy season from May to October. Latosol soils are dominant at 106 this research site and have an average $\mathrm{pH}$ around 5.

The dominant vegetation type is that of tropical seasonal dry rainforests, which differs 108 from lowland tropical rainforests because of a consistent annual dry season. This vegetation type 109 contains a mixture of evergreen and deciduous trees and deciduous trees do not senesce leaves at 
110 the same time so canopy cover remains intact throughout the year. The forest canopy can be

111 divided into three sublayers. The dominant overstory layer ranges from approximately $35-40 \mathrm{~m}$ in

112 height and is typically comprised of Pometia tomentosa, Terminnalia myriocarpa, and Garuga

113 florobunda var. gamblai. The mid-canopy layer ranges from $15-30 \mathrm{~m}$ and typically consists of

114 Barringtonia macrostachya, Chisocheton siamensis, Gironniera subaequalis, and Beilschmeidia

115 brachythyrsa. The subordinate layer ranges from 3-10 m and is typically comprised of Millettia

116 laptobotrya, Garcinia cowa, Drypetes indica, Myristica yunnanensis and Mezzettiopsis creaghii.

\section{Experimental design}

118 We sampled woody material from fallen trees, fallen large branches and snags to test the effects 119 of physical position and nutrient concentrations on decay rates. We obtained each material type 120 with end diameters between $8-10 \mathrm{~cm}$ during a biomass survey of this tropical seasonal rainforest 121 (Lü et al. 2010) from three 1 ha plots. The materials are a mixture of different tree species in 122 those three plots and represented the major tree species. Only newly formed, lightly decayed 123 materials were selected and brought back to our lab for further processing. These were identified 124 based on physical and visual characteristics that included evidence of insect use, presence of 125 saprotrophic fungi, attached bark and twigs, and friable sapwood or heartwood. The materials 126 were cut into $20 \mathrm{~cm}$ segments, weighted freshly, and stored at room temperature before 127 deployment. Five samples of each type of materials were oven dried at $80^{\circ} \mathrm{C}$ for 48 hours to 128 obtain the water content (\% Water of Wet weight). The initial dry mass of all materials was then 129 calculated using their fresh weight and the average water content of the five oven-dried samples.

Five fresh pieces of fallen tree, large branch, and snag material were combined as a 131 sample and deployed at our field site. Fallen tree and large branch material were put in litter bags 132 with $1 \mathrm{~mm}$ mesh to exclude wood consuming insects. Snag material was tied together with nylon 133 rope for hanging to simulate standing conditions. A total of 60 replicates were made for each type 
134 of material. We utilized a slope adjacent to a $\mathrm{CO}_{2}$ flux tower so our estimates could be correlated 135 with environmental measurements (i.e., soil temperature, soil moisture, air temperature) and to 136 allow future integration of our findings into net ecosystem carbon balance research and modeling.

137 Five transects perpendicular to the slope, $10 \mathrm{~m}$ apart from each other, were stratified from the 138 bottom to top of the slope. The starting location of each transect was randomly located. Twelve 139 litter bags containing log and large branch material were placed on the ground along each transect 140 about $5 \mathrm{~m}$ apart in January, 2006. Snag material was hung on a tree nearby each litter bag sample $141 \quad 1.5 \mathrm{~m}$ above ground.

Our initial estimates for all components of this research were conducted in January 2006

143 when the woody material was first collected. We visited the field site every three months for 144 sampling, beginning in April 2006, for a period of three years. One bag of each material was 145 randomly selected for sampling from each transect, for a total of five samples during each visit. 146 Each sample was first collected to estimate respiration rate using the dynamic, closed-chamber 147 method. A $22 \mathrm{~L}$ plastic bucket was used as the dynamic chamber. The bucket was sealed and two 148 rubber tubes were connected to a Li-cor 820 infra-red $\mathrm{CO}_{2}$ analyzer ( $\mathrm{Li}$-cor, USA). After the $\mathrm{CO}_{2}$ 149 concentration stabilized, we recorded these concentrations in ppm for $5 \mathrm{~min}$. We then collected 150 the samples for further lab analyses. All dirt, fruiting bodies and other debris were removed from 151 the retrieved samples. All samples were oven-dried at $80^{\circ} \mathrm{C}$ for 48 hours to obtain the low-weight 152 equilibrium moisture content. Following drying, the weight of each piece within a sample was 153 recorded for estimates of mass loss. Oven dried samples were ground with a Wiley mill and 154 filtered through a \#40 mesh sieve. Carbon and $\mathrm{N}$ concentrations of all samples were analyzed 155 with a PE-2400 CHN analyzer (Perkin-Elmer, Foster City, USA) and P concentration was 156 determined by persulfate oxidation followed by colorimetric analysis.

\section{Statistical Analyses}


158 We estimated carbon flux from woody detritus for fallen tree, fallen large branch and snag 159 material. $\mathrm{CO}_{2}$ flux was calculated using the following equation:

$$
F=\frac{P \times T_{0}}{P_{0} \times T \times 22.4} \times V \times d c / d t \times 10^{6} / m
$$

160 in which $\mathrm{F}$ is the $\mathrm{CO}_{2}$ flux $\left(\mu \mathrm{mol} \mathrm{kg} \mathrm{kg}^{-1}\right)$; $\mathrm{P}$ and $\mathrm{T}$ are the air pressure $(\mathrm{Pa})$ and temperature $(\mathrm{K})$ at 161 the time of measurement; $\mathrm{P}_{0}$ and $\mathrm{T}_{0}$ are air pressure and temperature in standard condition (273.15 $162 \mathrm{~K}$ and $100 \mathrm{kPa}$, respectively); $\mathrm{V}$ is the volume of the chamber, $\mathrm{m}$ is the dry mass of the material, $163 d c / d t$ is the slope of $\mathrm{CO}_{2}$ concentration against time $\left(\mathrm{ppm} \mathrm{s}^{-1}\right)$. We estimated this slope with 164 simple linear regression using R (R Core Team 2013).

We evaluated the relationship between environmental variables and heterotrophic $\mathrm{CO} 2$ 166 flux $\left(\mathrm{R}_{\mathrm{h}}\right)$ for each year of our sample period. Correlations between $\mathrm{CO}_{2}$ flux and soil temperature, 167 air temperature, soil moisture and relative humidity were estimated using Pearson's product168 moment correlation coefficients (r). Pearson's correlation coefficients were calculated for each 169 year (2006, 2007 and 2008) and all three years combined in R, and each metric was tested for $170 \quad$ significance at an $\alpha \leq 0.05$.

171 We estimated the annual decay-rate constant for fallen tree, fallen large branch and snag 172 material across our three years sampling period. We assumed a negative exponential model for 173 decomposition of each material type (Means et al. 1980). The model has the following form:

$$
Y=e^{-k t}
$$

174 in which $\mathrm{Y}$ is the proportion of initial mass remaining, $\mathrm{t}$ is the decay time expressed as a year in 175 this study, and $\mathrm{k}$ is the decay-rate constant. The decay-rate constant for all material was based on 176 mass loss from the oven-dried samples collected every three months. We used simple linear 177 regression in $\mathrm{R}$ to estimate log-transformed mass estimates as a function of time with the slope of 178 the line representing the decay-rate constant. 
180 every three months throughout the study period. All five samples for each type of material were

181 averaged together for all nutrients. We summarized $\mathrm{N}$ and $\mathrm{P}$ concentrations as both absolute

182 amounts $\left(\mathrm{mg} \mathrm{g}^{-1}\right)$ and percent of initial estimates. We also quantified C:N and C:P ratios across

183 our sampling period and report mean values across all five samples for each type of material.

185 Results

186 We observed seasonal variation in $\mathrm{CO}_{2}$ flux for all three woody detritus types. Temperature and

187 moisture estimates were typical of the seasonal rainforests during our three-year study period.

188 Soil and air temperature peaked in July or August concurrent with maximum soil moisture.

189 Relative humidity didn't fluctuate much and remained high throughout the year (Fig 1). The $\mathrm{CO}_{2}$

190 flux for all materials were higher in wet season than dry season across all three years. The highest

$191 \mathrm{CO}_{2}$ flux for fallen tree and large branch material did not coincide with the peak temperature and 192 moisture conditions, but rather occurred between April and June (Fig. 2). In fact, we observed 193 slight declines in $\mathrm{CO}_{2}$ flux of fallen tree and branch material by July in 2006 and 2007 when peak 194 moisture and temperatures were observed. $\mathrm{CO}_{2}$ flux for snag material was statistically correlated 195 with soil temperature, soil moisture and air temperature throughout our sampling period, while 196 respiration rates of fallen tree and branch material was only statistically correlated with these 197 factors in the final year of sampling (Table 1). Precipitation did not correlate well with all the 198 materials in the three years or combined, except for the respiration of snag material during 2008. $199 \mathrm{CO}_{2}$ flux for logs and branches increased slightly over the three years, while the respiration of 200 snags declined significantly in 2008. In 2006 and 2007, the respiration rate of snag material 201 during the wet season was higher than that of fallen tree and branch material, but was much lower 202 in 2008. 
Decay rates varied by substrate type and decay position (Fig 3). The decay-rate constant

(k) for fallen tree, large branch and snag material were $\mathrm{k}=0.606 \pm 0.020 \mathrm{yr}^{-1}, 0.316 \pm 0.012 \mathrm{yr}^{-1}$ and $0.268 \pm 0.008 \mathrm{yr}^{-1}$, respectively ( $\mathrm{p}<0.001$ for all three materials). After three years, fallen tree, large branch and snag material lost $87 \%, 68 \%$ and $60 \%$ of their original mass, respectively.

207 The decay rate of fallen tree material was similar to that of the other two materials during the first 208 six months of sampling, but exhibited an accelerated decay rate thereafter (Fig. 3).

The carbon concentration of all materials did not vary much in the first year, but decreased significantly thereafter (Fig 4). After three years, the carbon concentration of fallen tree 211 material dropped from an average of $510 \mathrm{mg} \mathrm{g}^{-1}$ to $291 \mathrm{mg} \mathrm{g}^{-1}$, or a decrease of $42 \%$, while large 212 branches and snags both showed a $23 \%$ decline (large branches from $505 \mathrm{mg} \mathrm{g}^{-1}$ to $380 \mathrm{mg} \mathrm{g}^{-1}$, 213 snags from $507 \mathrm{mg} \mathrm{g}^{-1}$ to $\left.391 \mathrm{mg} \mathrm{g}^{-1}\right)$. 219 by weighting $\mathrm{N}$ estimates, fallen tree material had $84.6 \%$ less $\mathrm{N}$ content than initial estimates, 220 while large branch and snag material lost on average $36.8 \%$ and $29.4 \%$, respectively. 225 increased $20.2 \%$ and $75.4 \%$, to an average of 0.23 and $0.21 \mathrm{mg} \mathrm{g}^{-1}$, respectively. With respect to 226 total P stores, snags remained stable until the end of the second year while logs and branches 
227 released $\mathrm{P}$ at the very beginning. As a result, snags only lost $29 \%$ of their total P stores, but $\operatorname{logs}$

228 and large branches lost $83.8 \%$ and $79.2 \%$, respectively. All substrates had similar temporal trends

229 in their C:N ratios, despite the C:N of logs being slightly higher (Fig 6). In contrast, the C:P ratio

230 of all substrates became more similar across our sampling period despite initial differences.

\section{Discussion}

233 Decay position significantly influenced the rate of decomposition for woody detritus in dry 234 tropical rainforests of Xishuangbanna, SW China (Fig. 2). Our estimates were comparable to 235 those observed in other dry tropical rainforests. For example, decay-rate constants for fine woody 236 detritus ranged from 0.151 to $1.019 \mathrm{yr}^{-1}$ (Harmon et al., 1995). Additionally, decay-rate constants

237 for coarse woody detritus in tropical forests of central Amazon ranged from 0.015 to $0.67 \mathrm{yr}^{-1}$ 238 (Chambers et al., 2000). As expected, our estimates for ground and standing decay rates were 239 faster than those observed in temperate deciduous forests (Fasth et al., 2011; Harmon 1995). We 240 did no observe an initial lag phase in our substrates like other studies (e.g., Fasth et al. 2011), 241 which may indicate one does not exist or our selection of already dead material may have already 242 progressed through this stage since we didn't know the exact time of death. A well-replicated, 243 manipulative study removing live trees to create these various substrates would be necessary to 244 determine if a lag phase exists or not.

245 Temperature is the most commonly used variable to capture woody decomposition in 246 biogeochemical models (Gough et al., 2007). However, in this study, only snag material had a 247 significant correlation with temperature. Our monthly estimates of heterotrophic $\mathrm{CO}_{2}$ flux $\left(\mathrm{R}_{\mathrm{h}}\right)$ 248 provide additional insights into the climatic controls on decomposition. A moderate amount of 249 moisture is believed to be critical for the survival of wood-degrading fungi (Carll and Highley, 250 1999), but excessive water excludes oxygen permeation into the material and effectively 
251 suppresses microbial activity (Rayner \& Todd 1980). This effect has been observed in Douglas-

252 fir forests where logs sheltered from rain exhibited higher respiration rate than exposed logs

253 (Progar et al., 2004). Soil respiration has also been shown to decline during periods of high soil

254 moisture in the tropical seasonal rainforest (Sha et al., 2004). Our results suggest that $R_{h}$ in fallen

255 tree and large branch material were constrained by high moisture conditions during the rainy

256 season. This is supported by the higher levels of $R_{h}$ on snag material where runoff reduces water

257 concentration in this material. We believe the higher $\mathrm{CO}_{2}$ flux observed for snag material during

258 the first year of sampling was reflective of ground materials having excessive water content due

259 to heavy rain and poor drainage during the annual rainy season. The initially high $\mathrm{CO}_{2}$ flux could

260 have been a result of wood endophytes containing potential wood decomposers with a

261 decomposing ability comparable to soil fungi (Parfitt et al., 2010, Song et al., 2016). Once the

262 labile $\mathrm{C}$ was consumed, respiration in snag appeared to be limited by water availability and the

263 colonization rate of fungal spores.

264 Our observed declines in C concentration of three substrates suggests that some newly

265 formed compound with lower carbon content was present. Formation of humic compounds from

266 decomposers, in which $\mathrm{C}$ was respired as $\mathrm{CO}_{2}$ while other elements were left, can form carbon

267 poor complexes. It is worth to note that determination of decay classes was often done by density

268 or observations (Onega et al. 2012), C concentration could be a potential indicator of decay stage

269 as shown in this study.

270 Nitrogen concentration has been shown to increase in the initial stages of decomposition,

271 while the relative change of $\mathrm{P}$ concentration depends on the initial $\mathrm{P}$ concentration in boreal

272 forests (Alban, 1993; Laiho \& Prescott, 2004). Such dependency and the converging of P

273 concentration was also observed in temperate forests (Laiho \& Prescott, 2004). The pattern we

274 observed in this study was probably a result of P limitation in tropical forests, which has been

275 observed by Vitousek (1984) and other studies at this same research site (Xue et al., 2003; Zheng 
276 2006). Materials originated from different positions differed in their initial $\mathrm{P}$ concentration. The

277 concentration of $\mathrm{P}$ in standing dead trees, started with lowest level, became similar as the two

278 ground materials after three years of decomposition. The initial P concentration turns out to be a

279 good predictor of $\mathrm{P}$ dynamics. Phosphorus can be allocated by cord forming fungi over long

280 distances (Wells \& Boddy, 1990), thus the convergence of P concentration and C:P may indicate

281 P limitation and resource relocation by wood-degrading organisms, most of which were white rot

282 fungi in tropical forests (Schilling et al., 2015). The three tree components used in this study also

283 reflect different $\mathrm{P}$ dynamics. The convergence of $\mathrm{P}$ concentration and $\mathrm{C}: \mathrm{P}$ ratio indicated an

284 equilibrium between wood-decay community and resource availability. As shown by Laiho et al.

285 (2004), a certain threshold of limiting resource could be a potential indicator of nutrient 286 accumulation or release.

Carbon and nutrient dynamics can be better predicted by incorporating multiple factors

288 into biogeochemical models for tropical seasonal rainforests. Temperature and C:N ratios are 289 commonly used to predict woody decay rates, but our results suggest neither was a good predictor 290 for all substrates we sampled. Even at regional scales, many environmental factors have been 291 shown to be poor predictors of wood decomposition (Bradford et al., 2014). In this study, the 292 decay position, as it relates to water availability, largely determined the rate of decomposition. 293 Many natural disturbances initially create snags so they are a prominent pool of CWD, at least 294 until they fall or break and become logs, so the type of woody detritus should be incorporated as a 295 predictor variable for estimating wood decomposition and C fluxes (Dunn and Bailey, 2015). We 296 have also shown that this can have significant implications on nutrient dynamics for these 297 systems.

\section{Conclusion}


300 Mass loss, respiration rate and nutrient dynamics of fallen trees, large branches and standing dead

301 trees were studied in their original decay position in a tropical seasonal rainforest of southwest

302 China. The decay rate of fallen trees was larger than the other two materials. Water availability

303 had a strong influence on the respiration rate of ground materials in rainy season, but the

304 respiration of standing dead trees was not suppressed, at least for the first two years. Decrease of

305 C concentration was observed for all the three materials at the late stage of this study. Phosphorus

306 concentration and $\mathrm{C}: \mathrm{P}$ showed convergent pattern after three years, indicating $\mathrm{P}$ limitation on

307 microbial activities in decomposition.

\section{Acknowledgements}

310 This study was financially supported by the Chinese Academy of Sciences 135 program (XTBG-

311 T03) and National Science Foundation of China (39800024 and 30370247). XT Lü acknowledge

312 the support from Youth Innovation Promotion Association of the CAS (2014174). We thank Yun

313 Lu and Defu Chen for help in field sampling and lab works. We appreciate the help from the

314 Biogeochemistry Laboratory of the Xishuangbanna Tropical Botanical Garden for elemental 315 analysis. 


\section{References}

318 Boddy, L., 2001. Fungal community ecology and wood decomposition processes in angiosperms:

319 from standing tree to complete decay of coarse woody debris. Ecol. Bullet. 49, 43-56.

320 Bradford, M.A., Warren. II R.J., Baldrian. P., Crowther, T.W., Maynard, D.S., Oldfield, E.E., 321 Wieder, W.R., Wood, S.A., King, J.R., 2014. Climate fails to predict wood decomposition 322 at regional scales. Nat. Clim. Chang. 4, 625-630.

Cao, M., Zhang, J., 1997. Tree species diversity of tropical forest vegetation in Xishuangbanna, SW China. Biod. Conserv. 1006, 995-1006.

325 Chambers, J.Q., Higuchi, N., Schimel, J.P., Ferreira, L.V., Melack, J.M., 2000. Decomposition 326 and carbon cycling of dead trees in tropical forests of the central Amazon. Oecologia. 122, $380-388$.

328

329

Fasth, B.G., Harmon, M.E., Sexton, J., White, P., 2011. Decomposition of fine woody debris in a deciduous forest in North Carolina. J. Torre.y Bot. Soc. 138, 192-206.

Franklin, J., Shugart, H., Harmon, M., 1987. Tree death as an ecological process. BioScience. 37, $550-556$.

Freschet, G.T., Weedon, J.T., Aerts, R., van Hal, J.R., Cornelissen, J.H.C., 2012. Interspecific differences in wood decay rates: insights from a new short-term method to study long-term wood decomposition. J. Ecol. 100, 161-170.

Harmon, M., Whigham, D., Sexton, J., Olmsted, I., 1995. Decomposition and mass of woody detritus in the dry tropical forests of the northeastern Yucatan Peninsula, Mexico. Biotropica. 27, 305-316. 
Harmon, M.E., 1982. Decomposition of Standing Dead Trees in the Southern Appalachian Mountains. Oecologia. 52, 214-215.

Laiho, R., Prescott, C., 2004. Decay and nutrient dynamics of coarse woody debris in northern coniferous forests: a synthesis. Can. J. For. Res., 777, 763-777.

Liu, W., Liu, W., Li, P., Duan, W., Li, H., 2010. Dry season water uptake by two dominant

Lü, X.-T., Yin, J.-X., Jepsen, M.R., Tang, J.-W., 2010. Ecosystem carbon storage and partitioning

Parfitt, D., Hunt, J., Dockrell, D., Rogers, H.J., Boddy, L., 2010. Do all trees carry the seeds of in decaying wood. Adv. Bot. Res. 7, 333-420. 
Schilling, J.S., Ayres, A., Kaffenberger, J.T., Powers, J.S., 2015. Initial white rot type dominance of wood decomposition and its functional consequences in a regenerating tropical dry forest. Soil Biol. Biochem. 88, 58-68. doi:10.1016/j.soilbio.2015.05.002

Seastedt, T., 1984. The Role of Microarthropods in Decomposition and Mineralization Processes. Annu. Rev. Entomol. 29, 25-46.

Sinsabaugh, R., Antibus, R., 1993. Wood decomposition: nitrogen and phosphorus dynamics in relation to extracellular enzyme activity. Ecology. 74, 1586-1593.

Song, Z., Kennedy, P., Liew, F.J., Schilling, J., 2016. Fungal endophytes as priority colonizers initiating wood decomposition. Funct. Ecol. DOI: 10.1111/1365-2435.12735

Vanderwel, M.C., Malcolm, J.R., Smith, S.M., 2006. An integrated model for snag and downed woody debris decay class transitions. For. Ecol. Manag. 234, 48-59.

Wells, J., Boddy, L., 1990. Wood decay, and phosphorus and fungal biomass allocation, in mycelial cord systems. New phytol. 116, 285-295.

Xue, J.Y., Tang J.W., Sha L.Q. \& Meng, Y., 2003. Soil Nutrient Contents and Their Characteristics of Seasonal Changes Under Shorea chinensis Forest in Xishuangbanna. Chin. J. Plant. Ecol. 27, 373-379.

Zheng, Z., Shanmughavel, P., Sha, L., 2006. Litter Decomposition and Nutrient Release in a Tropical Seasonal Rain Forest of Xishuangbanna, Southwest China. Biotropica. 38, 342347. 
Table 1. Correlation of respiration rate and environmental factors of three materials

\begin{tabular}{|c|c|c|c|c|c|}
\hline Year & Materials & Soil T & Air T & Soil M & Precipitation \\
\hline \multirow{3}{*}{$1^{\mathrm{st}} \mathrm{yr}$} & Fallen trees & 0.54 & 0.51 & 0.45 & 0.204 \\
\hline & Large branches & 0.53 & 0.52 & 0.46 & 0.209 \\
\hline & Standing dead & 0.78 & 0.74 & 0.94 & 0.550 \\
\hline \multirow{3}{*}{$2^{\text {nd }} \mathrm{yr}$} & Fallen trees & 0.52 & 0.46 & 0.32 & -0.167 \\
\hline & Large branches & 0.50 & 0.49 & 0.38 & 0.030 \\
\hline & Standing dead & 0.75 & 0.68 & 0.66 & 0.492 \\
\hline \multirow{3}{*}{$3^{\mathrm{rd}} \mathrm{yr}$} & Fallen trees & 0.56 & 0.66 & 0.51 & -0.096 \\
\hline & Large branches & 0.66 & 0.68 & 0.23 & 0.349 \\
\hline & Standing dead & 0.82 & 0.83 & 0.56 & 0.681 \\
\hline \multirow{3}{*}{ All yrs } & Fallen trees & 0.46 & 0.48 & 0.39 & -0.009 \\
\hline & Large branches & 0.52 & 0.53 & 0.33 & 0.149 \\
\hline & Standing dead & 0.63 & 0.59 & 0.59 & 0.438 \\
\hline
\end{tabular}

Values in bold are significant at an $\alpha \leq 0.05$.

379 


\section{$381 \quad$ Figure legends}

382 Figure 1. Environmental factors of the study site in Xishuangbanna between from 2006 to 2008.

383 Figure 2. The respiration rates of fallen trees, large branches and standing dead trees from 2006 to 384 2008. The error bars are standard deviations.

385 Figure 3 . The change of mass remaining of fallen trees, large branches and standing dead trees

386 from 2006 to 2008.

387 Figure 4. Change in average carbon concentration of fallen trees, large branches and standing 388 dead trees from 2006 to 2008.

389 Figure 5. Dynamics of concentration and total amount of nitrogen and phosphorus of fallen trees, $390 \quad$ large branches and standing dead trees from 2006 to 2008.

391 Figure 6. Change of C:N and C:P of logs, large branches and snags from 2006 to 2008. 


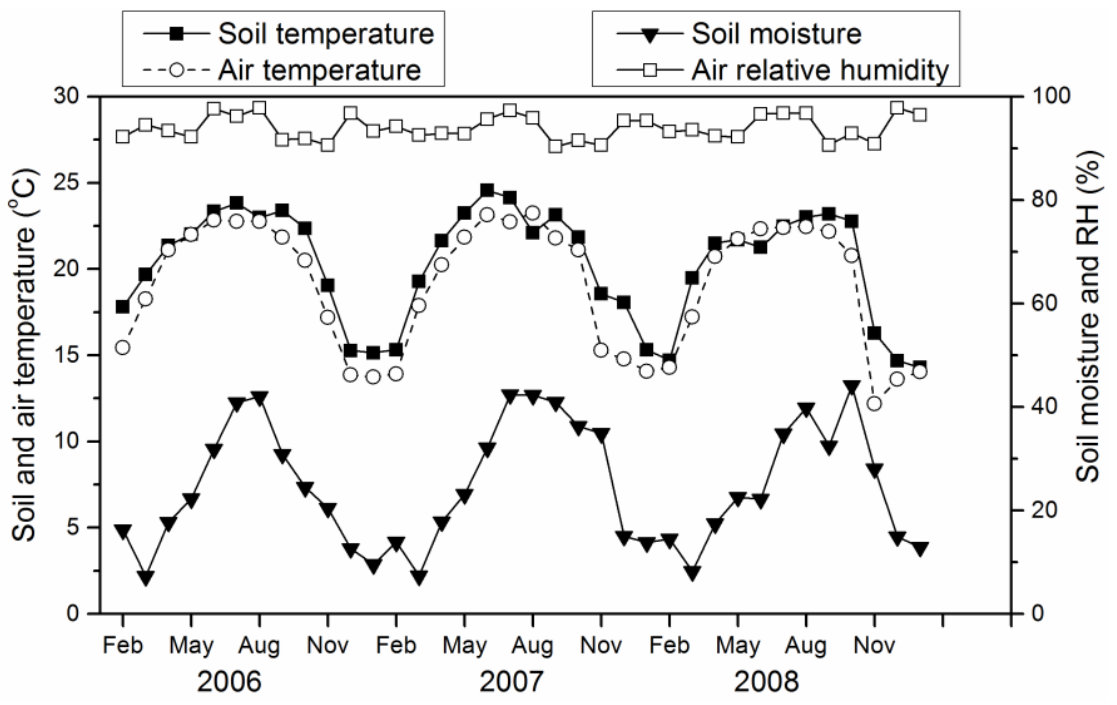

397 Figure 1. Environmental factors of the study site between from 2006 to 2008. 

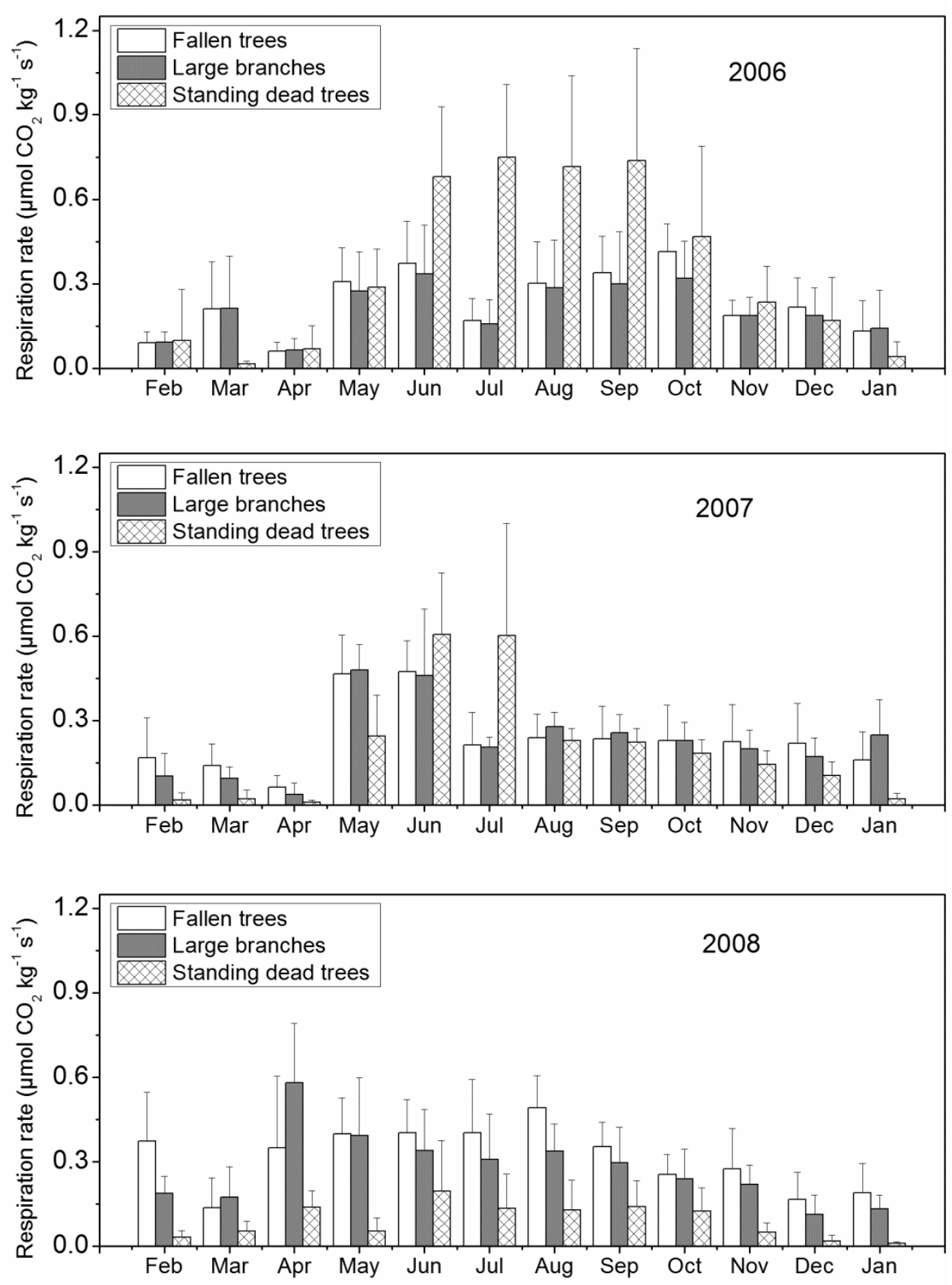

400 Figure 2. The respiration rates of fallen trees, large branches and standing dead trees from 2006 to 401 2008. The error bars are standard deviations. 


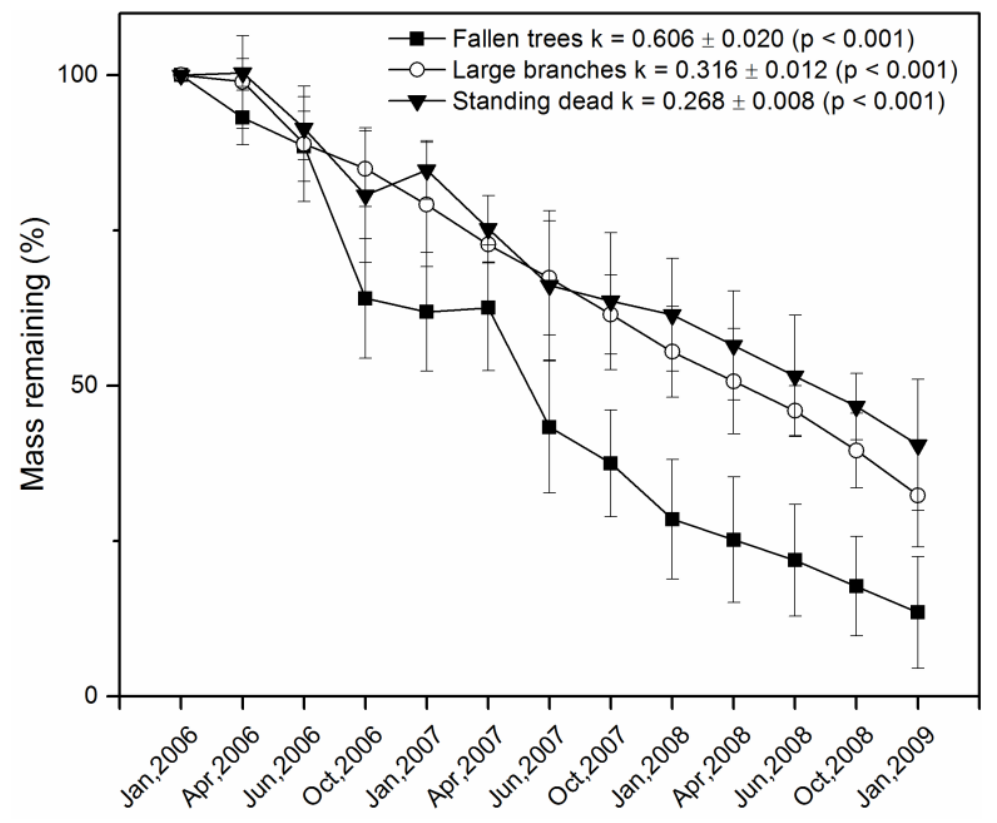

404 Figure 3 . The change of mass remaining of fallen trees, large branches and standing dead trees 405 from 2006 to 2008.

406
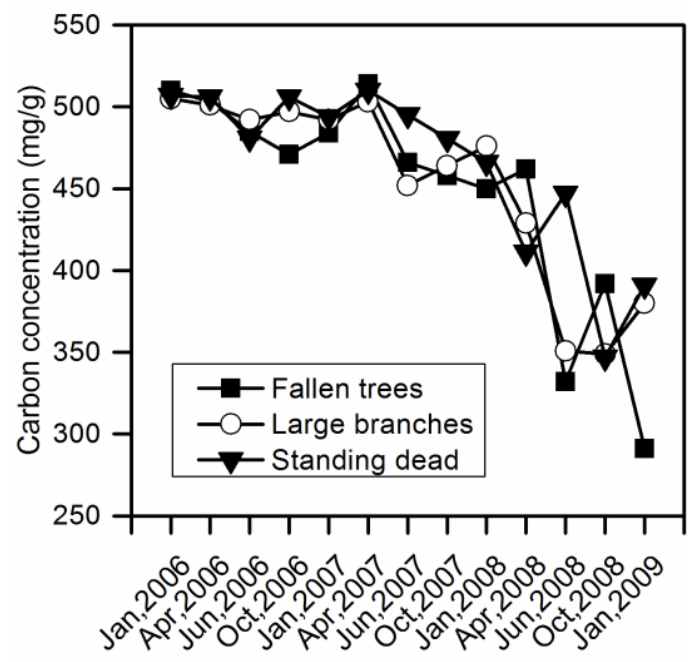

Figure 4. Change in average carbon concentration of fallen trees, large branches and standing dead trees from 2006 to 2008 . 


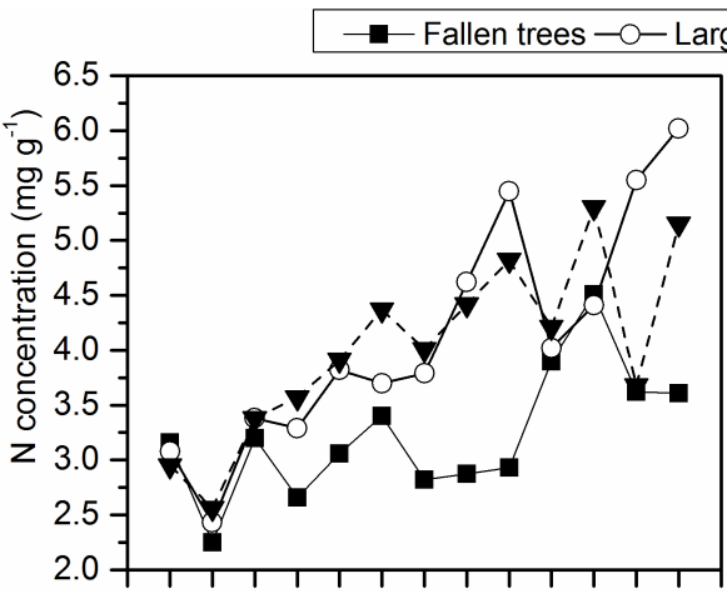

Standing dead
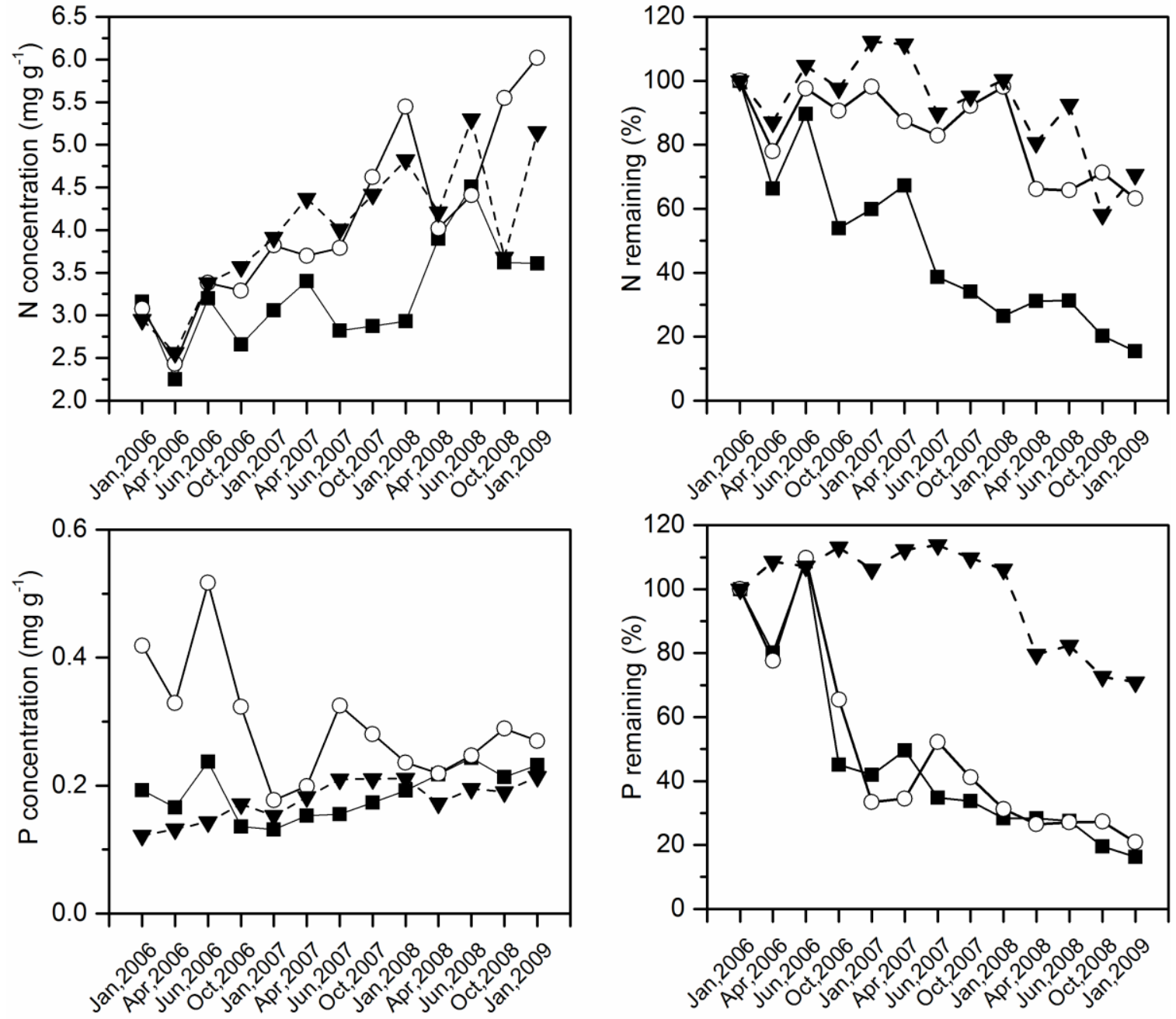

413 Figure 5. Dynamics of concentration and total amount of nitrogen and phosphorus of fallen trees,

$414 \quad$ large branches and standing dead trees from 2006 to 2008. 

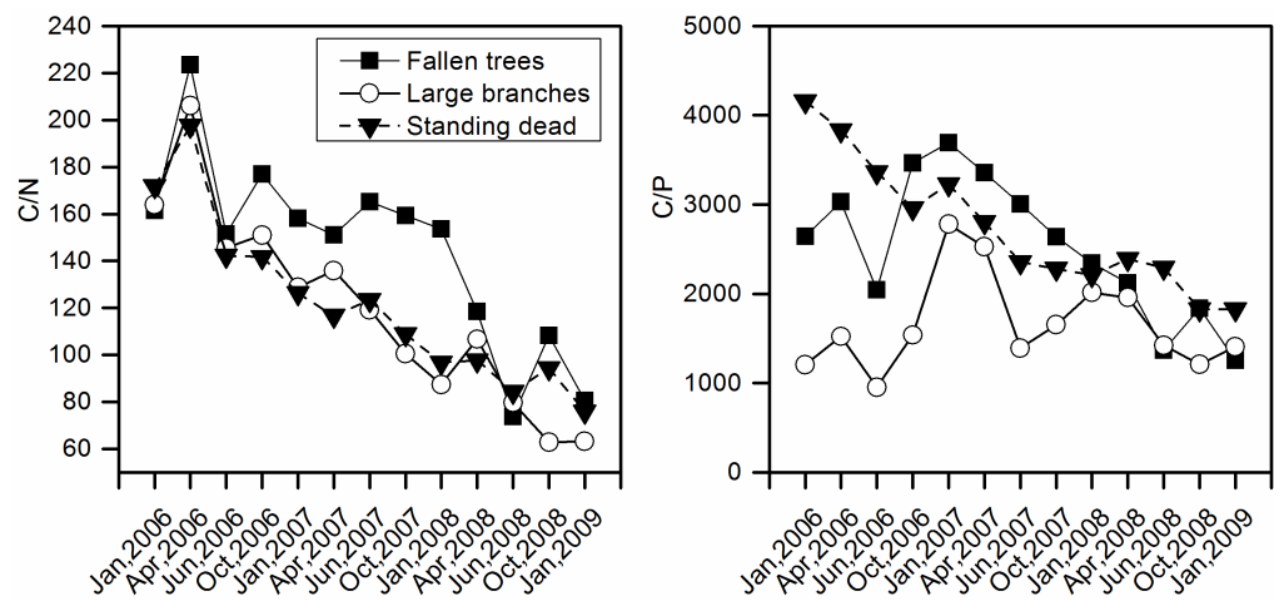

419 Figure 6. Change of C:N and C:P of logs, large branches and snags from 2006 to 2008. 